\title{
测绘新技术在国土测绘工程中的运用分析
}

\section{Application Analysis of New Technology of Surveying and Mapping in Land}

\section{Surveying and Mapping Project}

\section{王振雄}

Zhenxiong Wang

河北省地矿局第四水文工程地质大队 中国·河北 沧州 061000

The Fourth Hydrologic Engineering Geological Brigade of the Land and Mineral Bureau of Hebei Province,

Cangzhou, Hebei, 061000, China

\section{1 引言}

随着中国社会经济的不断发展,科学技术有了显著进步, 以往的测绘技术已不再满足应用的需要，很多新的测绘技术 被研发出来。从目前看,中国研发的每一个测绘新技术都有不 同的应用效果,它们适用于不同的环境中,使用方法也具有较 大差异。

\section{2 测绘技术在国土测绘工程中产生效用} 的具体表现

测绘技术的存在能够帮助人们了解国土信息, 同时,保证 所获取的相关信息数据是真实可靠的。测绘技术在国土现状 调查、地籍调查、国土行业监测以及日常业务开展等多方面发 挥了不可或缺的作用。中国第三次土地调查正在实施过程中, 遥感及地理信息等技术依然是项目开展的主要技术支撑; 随 着城市化建设的不断加快, 长期发展消耗了大量的资源, 就算 中国地大物博, 也逐渐出现了土地资源贾乏问题,城市可利用 土地逐渐减少，因土地分配问题而产生土地纠纷的现象频频 发生, 为了能有效解决此类问题, 就需要明确土地的权属以及 范围, 积极开展土地的确权工作; 国土机构日常工作中的土地 整治方案设计环节, 需要相关的工作人员在方案设计开展前, 要先进行地形测绘、地类调查、权属调查等相关工作,在此基
础上, 进行相关工程设计工作, 数据的详实性直接影响项目整 体质量 ${ }^{[1]}$

\section{3 测绘新技术在国土测绘工程中的应用}

\section{1 全球定位系统在国土测绘工程中的应用}

GNSS 简称为全球导航卫星系统, 该技术的运行原理是结 合卫星接收以及发送地理位置信息。将 GNSS 技术应用到国 土测绘工程中, 不仅能够明确测绘标的位置, 还能帮助相关测 绘人员获得速度、时间等方面的信息。GNSS 技术拥有动态测 量和静态测量两方面内容, 其中静态测量技术测绘结果可以 精确到毫米, 保障了实际测绘过程中所获数据的精准度, 同时 也确保测绘不会受到外界环境的影响, 提高了测绘工作的效 率和质量, 进而推动国土测绘工程的顺利开展。但是随着社会 的不断发展, 动态测量已经成为测绘工程的主流, 所以需要 相关的研究人员深人研究动态测量技术, 将其作用充分发挥 出来。

GPS 属于 GNSS，其是目前世界上运用较广的一类技术， 随着科学技术的不断发展, GPS 逐渐被其他国家引进, 中国也 对其应用做了进一步研究, 且成效显著, 推动了该技术在各行 各业中的应用。与普通的定位软件相比, GPS 在很多方面具有 一定的优势, 首先是不容易受到外界的干扰, 保密性较好, 除 
了能快速定位, GPS 还可以实时跟踪目标, 但目前, 在国土测 绘工程中,该技术起到了很大作用, 就是因为应用的普及,使 得该技术的操作越来越简单, 相关测绘人员都可以操作, 这对 做好测绘外业、处理数据以及选点等工作具有积极作用。

\section{2 地理信息系统在国土测绘工程中的应用}

地理信息系统, 其实就是人们常说的 GIS, 这是一种涵盖 地理学、地图学以及计算机技术等很多学科内容的综合性技 术。社会各个领域中都有该技术的身影，它不仅被应用到国土 测绘工程中, 同时, 像国防建设、水利工程等方面也会涉及到 对该技术的应用,甚至连城市发展规划也离不开此技术的渗 透。GIS 可以对地理信息进行分析和处理,并且还能同时处理 多个阶段的信息数据，而其他技术在开展该项工作时必须 分阶段完成, GIS 技术的出现节省了时间, 极大地提高了工作 效率[2]。

\section{3 遥感技术在国土测绘工程中的应用}

遥感技术又被称为 RS, 该类技术工作的原理主要是依靠 电磁波处理数据, 能够在最短的时间内获取较多的数据, 且有 效规避掉外界存在的干扰因素,完成地图成像的工作。中国传 统的国土测绘工程主要采用手绘地图, 但是由于人存在一定 的限制, 所以无法绘制出比较精确的地图, 但是, RS 技术的出 现不仅能够保证地图成像的精准性, 而且还能在一定程度上 降低成本费用,具有较好的应有优势 $[3]$

\section{4 摄影测量技术在国土测绘工程中的应用}

该类技术主要是使用比较常用的摄影方式分析、处理相 应的数据, 并从数据中获取有价值的信息内容, 摄影测量技术 一般包括技巧性摄影和数字化摄影, 而要想让整体测量的质 量得到保证, 就需要择优选取合适的摄影机器, 保证各个方面 的需求都能与应用要求一致, 而且还要有效结合计算机技术,
这样能够在一定程度上减少出现一些不必要的问题,比如, 测 绘人员可以不用频繁地进入施工现场进行勘查, 只需要利用 好计算机对摄像进行深入的分析和处理。

\section{4 国土测绘工程的发展展望}

从目前来看, 国土测绘工程的发展前景较好, 无论是 CORS 系统的建立, 还是现代城市建设方面, 国土测绘工程都 能在其中发挥着巨大效用, 加强国土测绘工程建设,既保证了 城市管理工作的顺利进行, 又推动城市实现自动化、智能化管 理。其次,近年来,已有很多新技术被研制出来,随之被投入到 使用当中, 这为工程测绘工作提供了保障, 但工程测绘的准确 性还是有待加强。之后还需要建设现代化数字图书馆, 以实现 资源共享, 将其价值充分展现出来。研究此方面的过程中, 其 主流方向包括空间摄影, 空间摄影融合了多种先进技术, 三位 一体是它的最大优势,但该技术还有很大的提升空间。

\section{5 结语}

综上所述, 国土测绘工程对社会经济发展具有重要意义, 近年来,中国投人大量资金、人才和技术以支持测绘工程的发 展，很多测绘新技术由此被开发出来，并应用到测绘工程中 去, 进而推动了测绘质量的提高。但应用过程中暴露出来很多 问题, 希望相关人员、机构能加强对这方面的研究。

\section{参考文献}

[1]谭正文.测绘新技术在国土测绘工程中的运用研究 [J].科技风, 2019(21):109

[2]刘海刚.测绘新技术在国土测绘工程中的运用探究 [J].建材与 装饰,2019(9):222-223.

[3]张雨,胡传顺,汪丽,等.测绘新技术在国土测绘工程中的运用研 究[J].西部资源,2018(5):129-130。 